\title{
Temporally Dissociable Contributions of Human Medial Prefrontal Subregions to Reward-Guided Learning
}

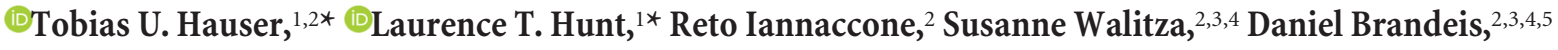 \\ Silvia Brem, ${ }^{2,3} \uparrow$ and Raymond J. Dolan ${ }^{1,6} \dagger$ \\ ${ }^{1}$ Wellcome Trust Centre for Neuroimaging, University College London, London WC1N 3BG, United Kingdom, ${ }^{2}$ University Clinic for Child and Adolescent \\ Psychiatry (UCCAP), University of Zurich, 8032 Zürich, Switzerland, ${ }^{3}$ Neuroscience Center Zurich, University of Zurich and ETH Zurich, 8057 Zurich, \\ Switzerland, ${ }^{4}$ Zurich Center for Integrative Human Physiology, University of Zurich, 8057 Zurich, Switzerland, ${ }^{5}$ Department of Child and Adolescent \\ Psychiatry and Psychotherapy, Central Institute of Mental Health, Medical Faculty Mannheim/Heidelberg University, 68159 Mannheim, Germany, and \\ ${ }^{6}$ Max Planck UCL Centre for Computational Psychiatry and Ageing Research, London WC1B 5EH, United Kingdom
}

In decision making, dorsal and ventral medial prefrontal cortex show a sensitivity to key decision variables, such as reward prediction errors. It is unclear whether these signals reflect parallel processing of a common synchronous input to both regions, for example from mesocortical dopamine, or separate and consecutive stages in reward processing. These two perspectives make distinct predictions about the relative timing of feedback-related activity in each of these regions, a question we address here. To reconstruct the unique temporal contribution of dorsomedial (dmPFC) and ventromedial prefrontal cortex (vmPFC) to simultaneously measured EEG activity in human subjects, we developed a novel trialwise fMRI-informed EEG analysis that allows dissociating correlated and overlapping sources. We show that vmPFC uniquely contributes a sustained activation profile shortly after outcome presentation, whereas dmPFC contributes a later and more peaked activation pattern. This temporal dissociation is expressed mainly in the alpha band for a vmPFC signal, which contrasts with a theta based dmPFC signal. Thus, our data show reward-related vmPFC and dmPFC responses have distinct time courses and unique spectral profiles, findings that support distinct functional roles in a reward-processing network.

Key words: activation time-courses; medial prefrontal cortex; reward prediction error; simultaneous EEG-fMRI

Significance Statement

Multiple subregions of the medial prefrontal cortex are known to be involved in decision making and learning, and expose similar response patterns in fMRI. Here, we used a novel approach to analyzing simultaneous EEG-fMRI that allows to dissociate the individual time courses of brain regions. We find that vmPFC and dmPFC have distinguishable time courses and time-frequency patterns.

\section{Introduction}

The medial prefrontal wall is important for reward-guided decision making, including learning and evaluating the incentive

Received Feb. 9, 2015; revised June 2, 2015; accepted June 20, 2015.

Author contributions: T.U.H., R.I., S.W., D.B., and S.B. designed research;T.U.H., R.I., and S.B. performed research;

T.U.H. and L.T.H. analyzed data; T.U.H., L.T.H., R.I., S.W., D.B., S.B., and R.J.D. wrote the paper.

This work was supported by the Swiss National Science Foundation (320030_130237) and the Hartmann Müller Foundation (1460); T.U.H. is supported by the Swiss National Science Foundation (151641), R.J.D. holds a Wellcome Trust Senior Investigator Award (098362/Z/12/Z), L.T.H. is supported by Sir Henry Wellcome Fellowship (098830/ Z/12/Z), and The Wellcome Trust Centre for Neuroimaging is supported by core funding from the Wellcome Trust (091593/Z/10/Z).

S.W. received speakers' honoraria from Eli Lilly, OPO-Pharma, Janssen-Cilag and Astra Zeneca in the last 5 years. The remaining authors declare no competing financial interests.

*T.U.H. and L.T.H. contributed equally to this work.

†S.B. and R.J.D. are co-senior authors.

This article is freely available online through the J Neurosci Author Open Choice option.

Correspondence should be addressed to either Tobias U. Hauser or Laurence T. Hunt, Wellcome Trust Centre for

Neuroimaging, 12 Queen Square, London WC1N 3BG, UK. E-mail: t.hauser@ucl.ac.uk or laurence.hunt@ucl.ac.uk. value of cues and actions (Rushworth et al., 2007, 2011; Schoenbaum et al., 2009; Wallis and Kennerley, 2010; Alexander and Brown, 2011; O’Doherty, 2011). Two key subregions are a ventral portion beneath the genu of the corpus callosum (vmPFC; in particular medial area 10) and a dorsal portion that encompasses dorsal anterior cingulate cortex (dmPFC; in particular area 24, sometimes referred to as dACC; Ongür and Price, 2000; Rushworth and Behrens, 2008; Haber and Behrens, 2014). Evidence that both regions are important in reward processing disguises potential unique and temporally dissociable contributions to reward-guided learning.

DOI:10.1523/JNEUROSCI.0560-15.2015 Copyright $\odot 2015$ Hauser, Hunt et al.

This is an Open Access article distributed under the terms of the Creative Commons Attribution License Creative Commons Attribution 4.0 International, which permits unrestricted use, distribution and reproduction in any medium provided that the original work is properly attributed. 
The anatomical connectivity and cytoarchitecture of these two regions show a clear demarcation (Ongür and Price, 2000; Haber and Behrens, 2014). However, unambiguous functional dissociation is more problematic, with conflicting accounts proposing overlapping functions (Rangel and Hare, 2010; Rushworth et al., 2011). In human functional MRI (fMRI) studies, vmPFC and dmPFC are often coactivated, but show anticorrelated activation patterns (FitzGerald et al., 2009; Hare et al., 2011; Nicolle et al., 2012; Boorman et al., 2013; Hauser et al., 2014a). Indeed, the observation that coactivation of multiple areas is common in reward processing (Vickery et al., 2011) renders it difficult to ascribe a specific functional role to a single area.

Coactivated brain regions can emerge from two opposing principles: Two brain regions may receive inputs from the same source (such as dopaminergic midbrain), and synchronously process the same information with similar temporal patterns. Alternatively, coactivation of multiple regions in human neuroimaging studies may reflect a temporal sluggishness of an fMRI signal. Resolving these possibilities would gain strength from a refinement in methods with better temporal resolution, such as EEG or MEG (Hunt et al., 2012, 2013; Hauser et al., 2014b). These modalities are limited in detecting signals from deep sources, especially where multiple areas respond to produce overlapping signals (Fig. 1A). As a consequence, decision-making studies often restrict themselves to single event-related components, such as the feedback-related negativity (FRN; Holroyd and Coles, 2002; Walsh and Anderson, 2012) or frontal midline theta (Cohen, 2011; Cavanagh and Frank, 2014; Cavanagh and Shackman, 2015), both traditionally associated with the dmPFC. Signals from vmPFC, however, are only rarely reported using electrophysiological techniques (Hunt et al., 2012, 2013; Harris et al., 2013; Lipsman et al., 2014), and are more difficult to localize as they can be obscured by more prominent signals arising in closer spatial proximity to recording electrodes.

Here we exploit the trial-by-trial variability in simultaneously recorded EEG and fMRI signal (Fig. $1 B$ ) to determine the unique contributions of brain regions to the EEG signal, enabling us to establish the time course of each region's response profile. We first show in a simulation how overlapping, correlated, sources can be misattributed as a singular dorsal midline source. We then show our technique can resolve time courses of visual and motor areas. In our main analysis, we dissociate contributions from vmPFC and dmPFC and show that the reward-locked activation in vmPFC precedes that of dmPFC. Moreover, we find that distinct frequency bands are evoked in each region, specifically theta oscillations within dmPFC and alpha within vmPFC.

\section{Materials and Methods}

\section{Participants and task}

Twenty-five healthy, right-handed humans ( 16 females, $29.9 \pm 7.4$ years) performed a probabilistic reversal learning task while simultaneous EEGfMRI was acquired. The study was approved by the local ethics committee, and all participants gave written informed consent. Data from 17 of the subjects has been reported previously using different analysis methods (Hauser et al., 2014b, 2015). Subjects performed a probabilistic reversal learning task (Fig. 1C; Hauser et al., 2014a,b, 2015) with two stimuli that were assigned either $80 \%$ or $20 \%$ win probability (50 Swiss Centimes). After 6-10 correct responses, the reward probabilities reversed (average number of reversals: $7.3 \pm 1.1$ ). The task consisted of 120 trials and 40 null trials. Each trial lasted $9000 \mathrm{~ms}$ on average. The cue stimuli were simultaneously presented for $2500 \mathrm{~ms}$ and participants could respond within $1500 \mathrm{~ms}$ and the selected stimulus was then highlighted by a frame for at least $1000 \mathrm{~ms}$. After a jittered interval (mean 2750 $\mathrm{ms}$ ), feedback (framed or crossed coin indicating win or loss) was pre- sented for $1000 \mathrm{~ms}$, again followed by a jittered intertrial interval (mean $2750 \mathrm{~ms}$, range $2000-4000 \mathrm{~ms}$ ). Further details of the task are provided by Hauser et al. (2014b).

\section{Trialwise fMRI-informed EEG analysis}

To understand the time course of regions activated in the fMRI, we exploited trial-by-trial variability of the EEG and fMRI signal to test for consistency in its covariation across modalities. With this approach, we can determine at each peristimulus time point how much trial-by-trial BOLD fluctuation within a given region covaries with the EEG signal. This allows us to make inferences about the activation time course of a specific brain region. Importantly, allowing multiple correlated sources to compete for variance in explaining the EEG data renders it possible to disaggregate the unique contribution of each region separately.

The analysis proceeded in several stages (Fig. 1B):

$f M R I-R O I$ definition and single-trial response estimation. To understand the temporal evolution of a given brain region, we first defined a region-of-interest (ROI) using an ordinary fMRI analysis (cf. fMRI acquisition and analysis, below). We first derived areas being activated for a specific contrast. For our initial visual and motor responses, we used a contrast for the presentation of the cues (GLM1, cf. fMRI acquisition and analysis, below), and the button presses (GLM2, cf. fMRI acquisition and analysis, below), respectively. For our main analysis of $\mathrm{dmPFC}$ and vmPFC, we analyzed the reward-prediction error signals during feedback (GLM1). This contrast activated $\mathrm{dmPFC}$, vmPFC, posterior cingulate cortex (PCC), and bilateral anterior insula (AI; Table 1; Fig. 1D). For each of these areas, we then extracted the time series for the complete experiment. To do so, we extracted the first eigenvector of the activation clusters as the time series, a standard procedure within SPM ("volume-of-interest" method), which removes nuisance regressors (here: pulse, movement, slow drifts) from the time series. We then estimated a trial-by-trial hemodynamic response function (HRF) of each region (detailed description below).

Multiple linear regression of single-trial fMRI responses onto EEG data. The estimated HRF response was collapsed across every trial and ROI to create a design matrix $\mathrm{X}^{\text {fmri }}$ with dimensions: $\left(n_{\text {ROIs }}+\right.$ intercept $) \times n_{\text {trials }}$ (cf. Results, Eq. 1). This was then used to predict the EEG-signal $Y_{\mathrm{e}}^{\text {eeg }}$ across all trials and time points (dimensions: $n_{\text {timepoints }} \times n_{\text {trials }}$ ). This was done for every electrode resulting in a contrast estimate $B_{\mathrm{e}}^{\text {eeg }}$ for every time point and electrode (dimensions: $\mathrm{n}_{\mathrm{ROIs}+1} \times n_{\text {timepoints }}$ ). The analysis of the time-frequency data were performed similarly. The time-frequency-analysis contained one additional dimension (size: $n_{\text {frequencies }}$ ), but the principle of regression across trials was the same. With this linear regression analysis, we only account for linear relationships between an EEG and BOLD signal, as in previous EEG-informed fMRI analyses (Debener et al., 2005; Eichele et al., 2005; Baumeister et al., 2014; Becker et al., 2014; Boecker et al., 2014; Hauser et al., 2014a,b; Iannaccone et al., 2015).

Group-level random-effects analysis of sensor-level data. Based on these fixed-effects results for each subject (Eq. 1), we ran a random-effects analysis calculating the consistency of these beta estimates $\left(B_{\mathrm{e}}^{\text {eeg }}\right)$ across subjects, analogous to the summary statistics approach standardly used in fMRI analysis (Holmes and Friston, 1998). We therefore converted each individuals' beta estimates into three-dimensional SPM images (2 spatial dimensions, 1 time dimension) and smoothed the images (image kernel: $10 \mathrm{~mm} \times 10 \mathrm{~mm} \times 20 \mathrm{~ms}$; Kilner and Friston, 2010). We used each subject's individual electrode placement (as defined by the fiducials $\mathrm{FPz}, \mathrm{PO}$, PO10; cf. EEG acquisition and analysis, below) relative to the head for optimal alignment across subjects. Random-effects analysis was then run within SPM and familywise error (FWE) correction was used for multiple-comparison correction.

\section{Learning model}

We used a Bayesian hierarchical learning model, the hierarchical Gaussian filter model (HGF; Mathys et al., 2011, 2014), to fit subjects' learning. This model is a Bayesian variation of classical reinforcement learning models (Rescorla and Wagner, 1972), which accounts for environmental volatility and adapts a trialwise learning rate accordingly (Behrens et al., 
A
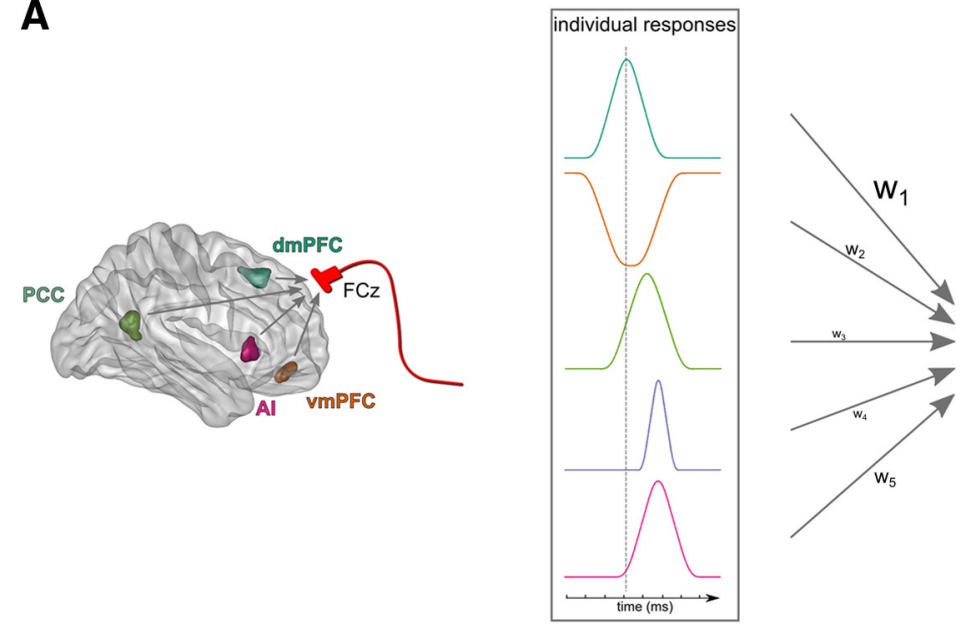

recorded response

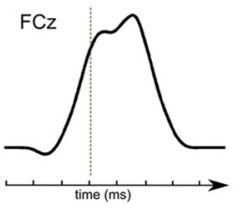

B

fMRI amplitudes for each ROI

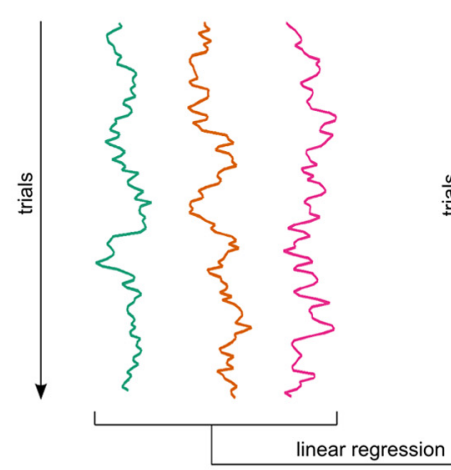

C

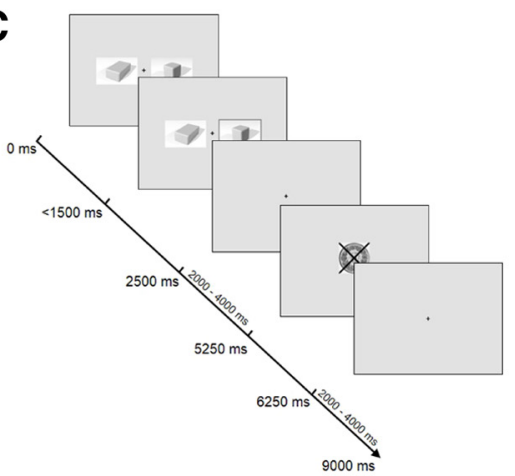

E

correlation between ROIs

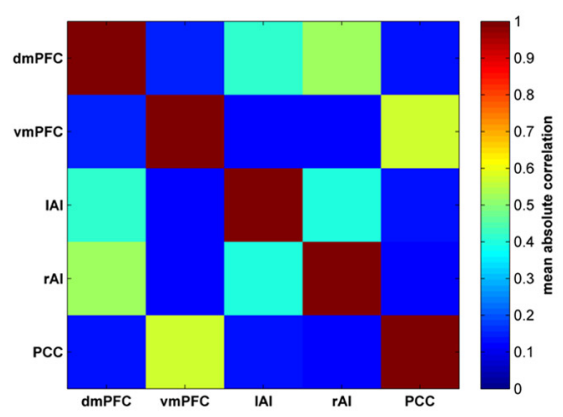

D
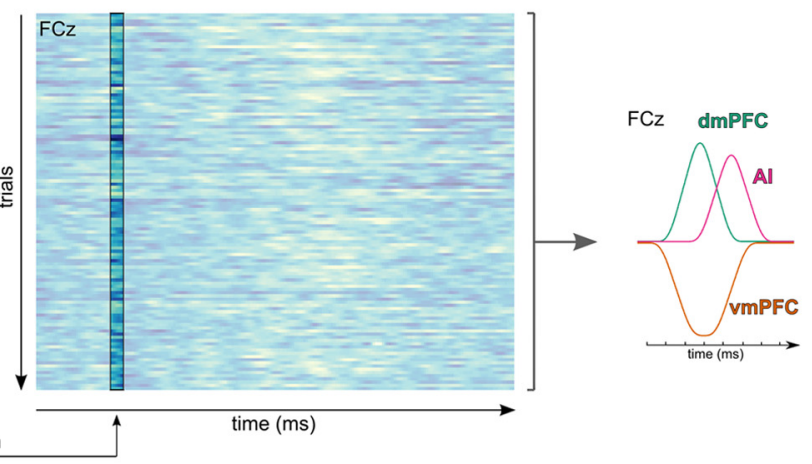

main fMRI effect of RPE

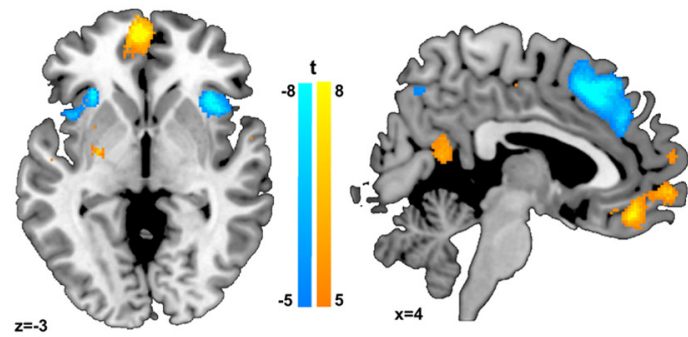

$\mathbf{F}$

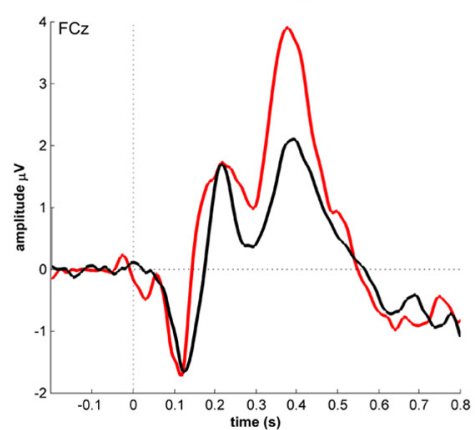

Figure 1. Contributions of multiple brain areas to the EEG signal and their parcellation using fMRI-informed EEG. $A$, fMRI studies of reward processing show a multitude of areas responsive to reward information, such as reward prediction errors (left). Hypothetically, each area has a specific time course and amplitude in response to a stimulus (middle). Electrical fields elicited by these individual activation patterns sum spatially and a mixture of these signals defines event-related potentials measured at scalp electrodes, such as frontocentral electrode $\mathrm{FCz}$ (right). The contribution of each area is governed by the strength of its activation and the spatial proximity to the electrode, such that the recorded signal is a weighted sum (Figure legend continues.) 
Table 1. RPE effects in the fMRI-analysis

\begin{tabular}{llllrrrr}
\hline Contrast & Region & Hemisphere & Cluster size & $x$ & $y$ & $z$ & Z-score \\
\hline RPE & vmPFC & Bilateral & 186 & -5 & 44 & -12 & 6.50 \\
& & & 156 & -2 & 57 & -5 & 6.14 \\
& PCC & Bilateral & 184 & -2 & -52 & 19 & 5.89 \\
- RPE & Al & Right & 172 & 36 & 18 & 0 & 6.25 \\
& dmPFC & Bilateral & 358 & 6 & 20 & 48 & 6.23 \\
& Al & Left & 27 & -30 & 23 & -3 & 5.92
\end{tabular}

RPE significantly (de-)activated vmPFC, dmPFC, PCC, and the Al. All these areas were entered into the fMRl-informed $\mathrm{EEG}$ analysis to determine the unique time courses of vmPFC and dmPFC. All coordinates are reported in MNI space. Areas reported at $p<0.05$ FWE-correction, $k>20$. RPE, Areas that increase activity with increasing RPEs; $-\mathrm{RPE}$, areas that increase activity with decreasing RPEs.

2007; Mathys et al., 2011). This model has been shown to outperform standard reinforcement learning models in many instances (Iglesias et al., 2013; Diaconescu et al., 2014; Hauser et al., 2014a; Vossel et al., 2014). It is worth noting that the prediction error signals generated by this model are closely correlated with those generated by more standard reinforcement learning models. Unsurprisingly, the cortical regions of interest isolated by the HGF model-based analysis of prediction errors in fMRI data (Fig. 1D) are similar to those identified using classic reinforcement learning models as shown in previous studies (Gläscher et al., 2009; Hauser et al., 2015).

\section{EEG acquisition and analysis}

EEG was recorded with a sampling rate $5 \mathrm{kHz}$ using MR-compatible DC-amplifiers (BrainProducts $\mathrm{GmbH}$ ) with 63 channels and two ECG electrodes for cardioballistic artifact removal. The scalp electrodes covered the 10-20-system plus these additional sites: FPz, AFz, AF2, FCz, CPz, POz, Oz, Iz, F5/6, FC1/2/3/4/5/6, FT7/8/9/10, C1/2/5/6, CP1/2/3/4/ $5 / 6$, TP7/8/9/10, P5/6, PO1/2/9/10, OI1/2, and left and right eyes (laterally and below the eyes). For a more even coverage, $\mathrm{O}^{\prime} / 2^{\prime}$ and $\mathrm{FP} 1^{\prime} / 2^{\prime}$ were located $15 \%$ more laterally to $\mathrm{Oz} / \mathrm{FPz}$. Fz was used as recording reference. The EEG clock was synchronized with the MRI scanner clock to ensure stable gradient artifacts for optimal MR artifact removal (Mandelkow et al., 2006).

The electrode positions of each subject were manually determined based on the T1 image, which was recorded while the participants were wearing the EEG cap. The electrode positions of FPz, PO9, and PO10 were then used as fiducials to coregister the electrode positions to the scalp.

Preprocessing was performed in Analyzer (v2.01, BrainProducts $\mathrm{GmbH}$ ). We performed MR-artifact removal using sliding average subtraction (Allen et al., 2000), and in-built cardioballistic artifact removal with manual inspection. The data were resampled to $256 \mathrm{~Hz}$ and filtered (0.1-30 Hz bandpass, $50 \mathrm{~Hz}$ notch). Ocular movement artifacts, remain-

\section{$\leftarrow$}

(Figure legend continued.) (as indicated by hypothetical weights, $\mathrm{w}_{1}-\mathrm{w}_{5}$ ) that overweighs sources close to the recording electrodes (here: $\mathrm{dmPFC}$ ). $\boldsymbol{B}$, Trial-by-trial fMRI-informed EEG analysis disentangles unique contributions of brain areas to the EEG signal. Using the hemodynamic response, we estimate fMRI activation of each brain region on every trial (left). Within a multiple-regression analysis, we then determine the peristimulus time when trial-by-trial fMRI activations best predict the EEG signal (middle). This enables us to recover the unique and individual time courses of these brain regions (right). However, a caveat is that the approach remains insensitive to temporal contributions that perfectly covary in the fMRI signal across trials. C, Participants engage in a probabilistic reversal-learning task where they learn which of two stimuli had the higher reward probability. One of the stimuli was assigned as the correct stimulus with a reward probability of $80 \%$. The other stimulus had a reward probability of $20 \%$. The reward was depicted by a framed 50 Swiss Centimes' coin, whereas a punishment was illustrated by a crossed coin. After $6-10$ correct responses, the reward probabilities reversed. The participants were informed about potential reversals but were not instructed on the timing of these reversals. D, fMRI activations for RPEs at feedback. Increasing RPEs were linked to engagement of vmPFC and PCC, whereas decreasing RPEs engendered activation in $\mathrm{AmPFC}$ and bilateral Al. $\boldsymbol{E}$, Average absolute correlations between ROIs activated in the RPE-fMRI-contrast. $\boldsymbol{F}$, Event-related potentials elicited over electrode $\mathrm{FC} z$, separated for rewards (black) and punishments (red). dmPFC, Dorsomedial prefrontal cortex; IAI, left anterior insula; PCC, posterior cingulate cortex; rAl, right anterior insula; vmPFC, ventromedial prefrontal cortex. ing MR and cardioballistic artifacts were removed using ICA. Trials exceeding $120 \mu \mathrm{V}$ were automatically excluded. Continuous EEG was re-referenced to average reference and subsequently exported to MATLAB (R2013B). Further analysis was performed using customized analysis scripts as well as fieldtrip (Oostenveld et al., 2011) and SPM M/EEG (www.fil.ion.ucl.ac.uk; Litvak et al., 2011) routines.

In this paper, we do not focus on the task-evoked potentials (ERPs), but on the effect of BOLD variability on the EEG signal. For completeness, however, we show the event-related EEG components for rewards and punishments in Figure $1 F$.

Time-frequency power-spectra analysis was performed in fieldtrip using "mtmconvol" with a Hanning taper between 0 and $1000 \mathrm{~ms}$, and 2 and $20 \mathrm{~Hz}$ frequency range ( 5 cycles per time window). The initial trialwise segments consisted of $5000 \mathrm{~ms}$ long epochs (prefeedback $2000 \mathrm{~ms}$ to postfeedback $3000 \mathrm{~ms}$ ) to allow an adequate TF-decomposition also in low frequencies. Power-spectra were baseline-corrected using a segment $1000-0$ ms before feedback presentation. To correct for multiple comparisons in the power spectrum, we used a cluster-based permutation test across the whole time-frequency spectrum using 1000 iterations and a cluster forming threshold of $\mathrm{t}> \pm 2$ (cf. Hunt et al., 2013).

\section{fMRI acquisition and analysis}

fMRI was recorded in a Philips Achieva 3T scanner and a 32-channel receive-only coil. The EPI sequence was optimized for minimal ventromedial signal dropout (TR: $1850 \mathrm{~ms}$, TE: $20 \mathrm{~ms}, 15^{\circ}$ rotation from ACPC; cf. Hauser et al., 2014b for further details). Additionally, a T1 wholebrain structural image was acquired. fMRI processing and analysis was performed in SPM 8 (www.fil.ion.ucl.ac.uk). Raw data were realigned to mean EPI and coregistered to the individuals T1 image. Normalization was performed using the new segmentation method and deformation field normalization. Subsequently, the normalized data were spatial smoothed with a $6 \mathrm{~mm}$ FWHM kernel. A more detailed description of the preprocessing is provided by Hauser et al. (2014a).

The key aim of the fMRI analysis in this paper was not to test specific novel hypotheses concerning RPE processing during reversal learning, but instead to generate ROIs that would subsequently be used to inform EEG analysis. We computed two separate GLMs to extract our specific ROIs.

GLM1. This GLM served as the primary analysis and was used to extract the reward prediction error (RPE)-related fMRI activations for the main joint fMRI-EEG analysis, as well as extract visual areas for the visual analysis. To isolate functional decision making ROIs, we entered the trialwise RPEs (variable $\delta_{1}$ from the HGF model, which denotes the difference of the posterior and prior mean) as parametric modulator at the onset of feedback presentation into the first-level GLM. Additionally, we entered the following nuisance regressors to improve model fit: movement parameters, choice value (variable $\hat{\mu}_{2}$ of chosen object; the prior mean of the chosen object, reflecting the chosen value in standard reinforcement learning schemes) at onset of the cue stimulus, and cardiac regressors (Glover et al., 2000; Kasper et al., 2009). The visual ROI was derived from the cue stimulus presentation regressor in this GLM.

GLM2. To investigate the hand motor area for our motor analysis, we computed an additional GLM that contained a regressor for all button presses and the following nuisance regressors: movement and pulse. For motor analysis, we entered the temporal and spatial derivatives. We derived the motor activity from an additional, separate GLM, because the subjects were allowed to choose freely after cue onset. Thus, the button press regressor was highly correlated with the stimulus onset regressor, which rendered it difficult to obtain a clear motor cortex activation.

For all fMRI-only analyses, we applied a peak-FWE threshold at $p<0.05, k>20$ to correct for multiple comparisons. The decision making network (GLM1) thus consisted of vmPFC and PCC which were positively associated with RPEs. Additionally, the dmPFC and bilateral AI were negatively correlated with RPEs (Table 1). In the analysis of the button presses (GLM2), we found the left handmotor area to be significantly activated by the first temporal derivative of the motor responses. This cluster then served as ROI for our motor anal- 


\section{A simulated dmPFC topography}

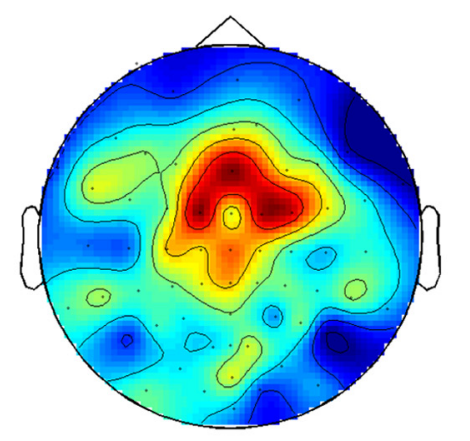

B simulated vmPFC topography

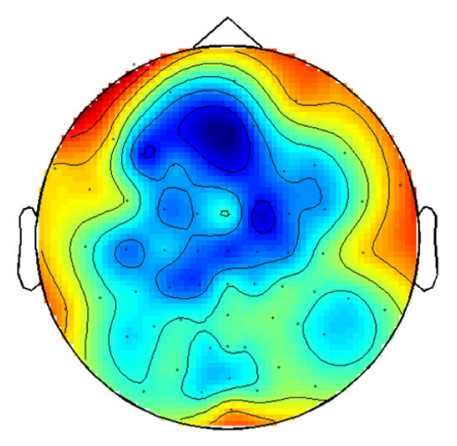

\section{C simulated common topography}

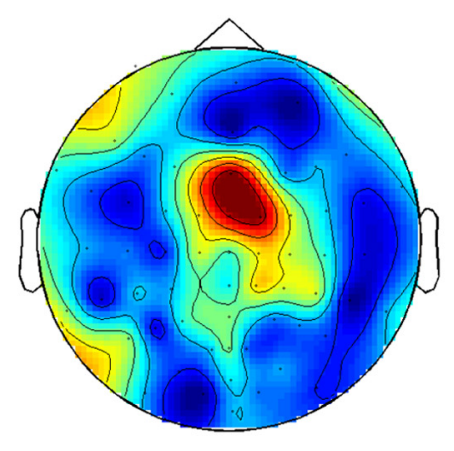

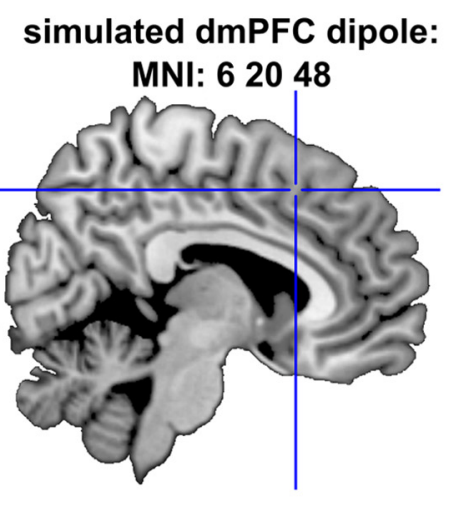

simulated vmPFC dipole: MNI: $-544-12$

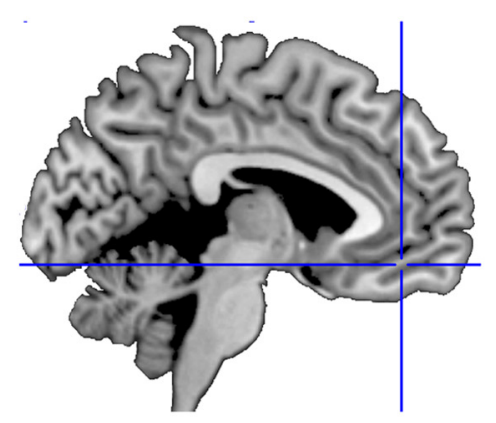

estimated dipole:

MNI: 13151

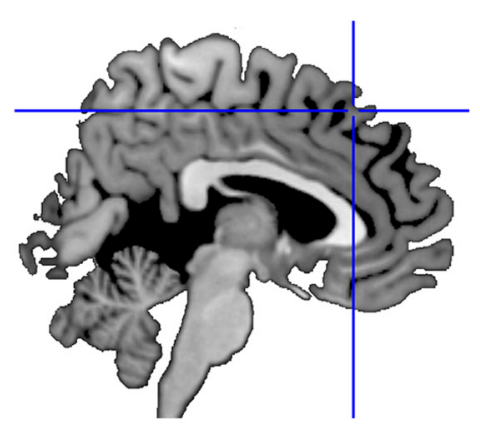

Figure 2. Overlapping activations of multiple brain areas bias inference and source localization in noninvasive neurophysiology. A simulated dipole from the $\operatorname{dmPFC~(A,~right)~shows~a~typical~midfrontal~topography~(left),~whereas~a~simulated~vmPFC~dipole~}$ $(\boldsymbol{B}$, right) displays a similar and overlapping topography (left), albeit with a broader spatial distribution reflecting its greater distance from the sensors. $\boldsymbol{C}$, The simulation of two, equally strong dipoles in vmPFC and $\operatorname{dmPFC}$ (same origins as $\boldsymbol{A}$ and $\boldsymbol{B}$ ) result in a topography, which is strongly dominated by the $\mathrm{dmPFC}$ signal (left). Source estimation of this topography, thus, falsely locates a single dipole in the $\mathrm{dmPFC}(\boldsymbol{C}$, right) and is unable to capture a contribution of the vmPFC.

ysis. In the visual analysis (GLM1), we found (in addition to primary visual areas) an occipitotemporal area containing fusiform gyrus to be highly active.

To estimate the trial-by-trial response of a given ROI, we first extracted the BOLD time-series (first eigenvector of the ROI, standard procedure in SPM "volume of interest" extraction) across the whole experiment. Nuisance artifacts as captured by our regressors-of-no-interest plus slow drifts $(>128 \mathrm{~s})$ and mean session amplitudes were removed from the time series.

To estimate the single-trial response amplitude, we up-sampled the data by factor 10 to a TR of $185 \mathrm{~ms}$ (using cubic spline interpolation) and then time-locked the signals from 0 to 8 s poststimulus. The up-sampling enabled us to fit the canonical SPM hemodynamic response function (and its first derivative) to the single-trial up-sampled data using linear regression. Using this method, we could estimate the amplitude of the HRF on each trial for each ROI without any overlap with the next trial (mean trial duration $9 \mathrm{~s}$; compare Fig. 1C), despite the sparse sampling of the fMRI signal $(\mathrm{TR}=1850 \mathrm{~ms})$. It is worth noting that a valid alternative method (particularly important for experiments with shorter trial durations and overlapping hemodynamic events) would be to model all trials in a single general linear model with HRF-convolved stick functions for each trial. In practice for our experiment, this produced very similar parameter estimates to the approach outlined above.

\section{Dipole simulations}

We sought to test (via simulation) whether equally strong sources placed in vmPFC and dmPFC would lead to both sources being visible in a conventional EEG analysis. Dipole simulations (Fig. 2) were performed using dipole simulation methods in fieldtrip. We used the standard template provided in SPM to generate the conductor tissue. We then used the peaks of our vmPFC and dmPFC ROIs as the MNI coordinates of our dipoles. The dipole momentum was set to [ [ $\left.\begin{array}{lll}0 & 0 & 1\end{array}\right]$ for dmPFC and [ $\left[\begin{array}{lll}0 & 0 & -1\end{array}\right]$ for vmPFC. For both separate dipole analyses (Fig. $2 A, B$ ), we used a fixed, equally strong signal and added $5 \%$ of noise. The same procedure was applied when simulating the two dipoles together (common simulation; Fig. $2 C)$. For fitting the dipole in the common simulation (Fig. $2 C$, right), we used the dipole fitting method in fieldtrip using the same head model as for the dipole simulation. To fit the dipole, we fitted one dipole and performed a linear grid search across the whole volume and report the best fitting source. We found (Fig. $2 C$, right) that the common topography for the mixed simulated dipoles was in fact estimated to originate solely from dmPFC. Similar results were obtained when both simulated sources were assigned with the same dipole momentum (data not shown). Such a localization method has frequently been used in conventional EEG studies, e.g., in studies investigating feedback-related negativity (cf. Walsh and Anderson, 2012). It thus shows the difficulty of detecting different sources with correlated and overlapping activation time courses.

Proof of principle: activation time course of visual and motor areas

To test the validity of our method, we applied it to a robust activation in left occipitotemporal cortex (Fig. 3A; containing fusiform gyrus, peak at MNI: $x=-36, y=$ $\left.-61, z=-2, t_{(24)}=19.02\right)$. This area showed strong fMRI activation in response to the presentation of visual stimuli using a standard fMRI analysis of stimulus presentation. Our fMRI-informed EEG analysis revealed that the EEG signal was strongly related to the fMRI data extracted from this visual ROI $\sim 190 \mathrm{~ms}$ after stimulus presentation (Fig. $3 A$, middle; $t_{(24)}=4.94$, peak-FWE corrected; $p=0.040$ for time window $0-300$ ms poststimulus), with a distinct topography showing its main effect over occipitotemporal electrodes. This finding is in agreement with a large body of previous EEG studies which found a distinct event-related signal, the N1 or N170, active $\sim 170-200$ ms after object presentation (Bentin et al., 1996; Thorpe et al., 1996; Rossion et al., 2000; Johnson and Olshausen, 2003). Source localization of the N1 to occipitotemporal areas 

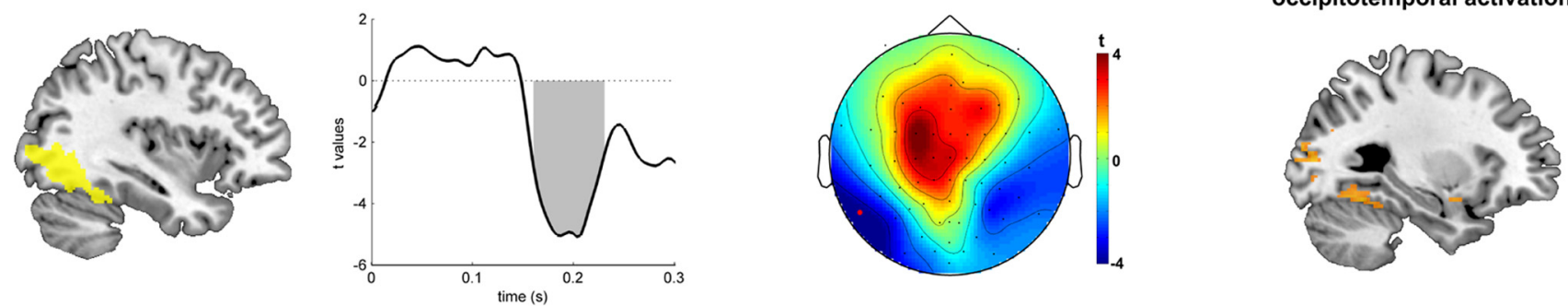

activation timecourse of motor ROI

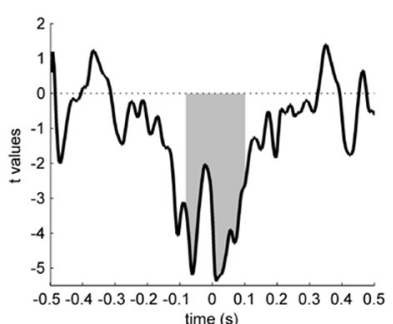

EEG topography elicited by motor ROI

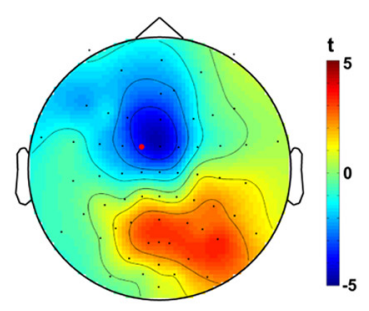

source localization of handmotor area

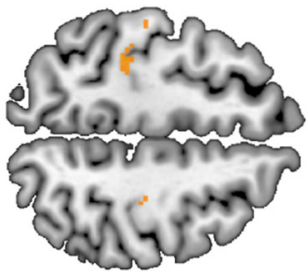

Figure 3. Validation of method in visual and motor areas. A, Left occipitotemporal region showed stimulus-related activations (left). Activity in this region was successfully associated with an EEG signal between 170 and $220 \mathrm{~ms}$ (shaded area depicts cluster-corrected significance) at occipitotemporal electrodes (middle), confirming the sensitivity of our approach (red indicates electrode used for time plot). Informed source localization confirmed sensitivity of topography (right). $\boldsymbol{B}$, Second validation of method. Right-handed button presses elicited activation of the left handmotor area (left), which was found to be active around the time of the button press with a typical midcentral topography (middle). Informed source localization localized again into the motor area (right).

in proximity of our functional ROI is widely reported (Hillyard and Anllo-Vento, 1998; Brem et al., 2006). In addition, the evoked topography showed a marked left-lateralization (Fig. 3A), confirming an assumption that the left-lateralized aspects of ordinary N1-topographies are generated within a left-hemispheric area. It is important to note that no prior spatial information was entered into our fMRI-informed EEG analysis and that this EEG scalp topography emerged naturally from the data. Based on this resulting topography, we then performed a priorinformed source-localization (cf. Informed source localizations, below) and found the peak source probability to relocalize within the original functional ROI (Fig. 3A, right; peak MNI: $x=-22, y=-86, z=12$ ).

As further confirmation for our method, we reconstructed the time course of the motor activity from the handmotor area. Here, we analyzed the fMRI activation at button press and derived a functional ROI which included the prominent " $\Omega$ sign" (Yousry et al., 1997), which defines handmotor area (Fig. 3B; peak activation at MNI: $x=-36, y=-30, z=$ 58; $\left.z=7.08 ; p_{\mathrm{FWE}}<0.001\right)$ and we determined its activity around the time of button presses in the task. We found that BOLD activation in this area significantly predicted EEG data between $\sim 80 \mathrm{~ms}$ before and $100 \mathrm{~ms}$ after button press (Fig. $3 B$, middle; cluster-extent FWE correction $p<$ 0.001 for time window -500 to 500 ms peristimulus; voxel height threshold: $t=3$; peak at $\left.20 \mathrm{~ms}, t_{(24)}=7.70\right)$. The topography showed a clear midcentral distribution in proximity of the handmotor area. Source localization, again, confirmed the reasonability of our resulting topography (Fig. 3B, right; peak MNI: $x=-34, y=-30, z=52$ ).

\section{Informed source localizations}

To examine the face validity of our analysis, we also localized the topographies which we received from our fMRI-EEG integration. Importantly, no spatial information entered into fMRI-informed EEG analysis, and therefore the method was completely uninformed about the spatial topography that might emerge in sensor-level EEG analysis.

For the source localization of our results, we used the group-level random effects topographies from our fMRI-informed EEG analysis. For each ROI, we ran an informed source localization in SPM. We used the time window that was found to be significant in the main analysis for the given ROI. The group topographies of the $t$ values during this time were then inverted. To generate the forward model, we used the mean of the normalized T1 images of all subjects. As group electrode positions, we used the mean of the subjects' individual fiducial positions which was then coregistered to the mean T1. The model inversion (minimum norm in combination with a smooth source covariance as provided in SPM: $\mathrm{COH}$; PST Hanning window; bandpass filter 0-48 Hz; Friston et al., 2008) was performed using a spatially informed, but unrestricted source localization using the fMRI-ROI as a prior. The prior we entered was the original ROI cluster, which was initially used for the fMRI-informed EEG analysis. This prior was adopted because we had strong assumptions on the origin of the topography and we wanted to evaluate whether the topography of our analysis confirmed or rejected our initial source localization. This approach leads to a relaxation of the shrinkage priors in this area, but does not restrict the source to be estimated at any area in the brain, i.e., it is less restrictive in the predefined region but allows for whole-brain sources. A striking example of this can be seen in Figure $4 D$, where the source localization for vmPFC also picks up a contribution from PCC, which is known to commonly coactivate with vmPFC in many studies of reward-guided learning and decision making (Clithero and Rangel, 2014).

\section{Results}

Determining activation time courses of brain regions

Simultaneous acquisition of EEG and fMRI provides a means to concurrently gather temporal and spatial information related to cognitive processing (Rosa et al., 2010; Huster et al., 2012). Most analysis methods rely on trial-by-trial variability of EEG data to localize the source of ERPs (Debener et al., 2005; Eichele et al., 2005; Baumeister et al., 2014; Becker et al., 2014; Boecker et al., 2014; Hauser et al., 2014a,b; Iannaccone et al., 2015). Here, we exploit a trial-by-trial variability in a local fMRI signal to determine the temporal activation and oscillatory pattern of specific, predefined, brain regions in recorded EEG tracings. Underlying all simultaneous EEG-fMRI analyses is an established assumption that electrical potentials as recorded by EEG, and brain activity as measured by the BOLD signal, show an approximately linear relationship (for review, see Rosa et al., 2010). If a brain region has an increased $\mathrm{fMRI}$ signal at a given trial, its electrical field potential will therefore also be increased, and vice versa.

Unlike traditional EEG-informed fMRI analyses or EEG source analyses, the analysis we implement is not meant to reveal 
A
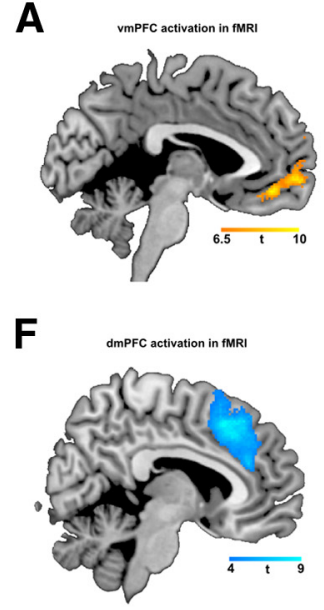

B

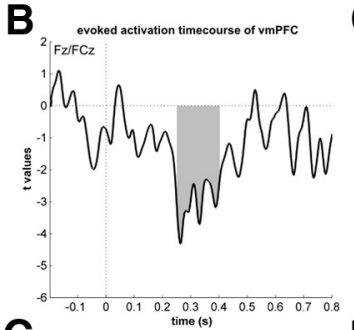

G

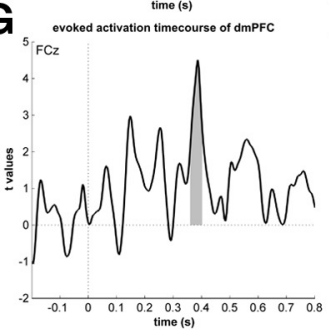

C

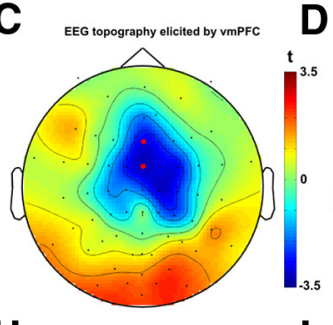

H

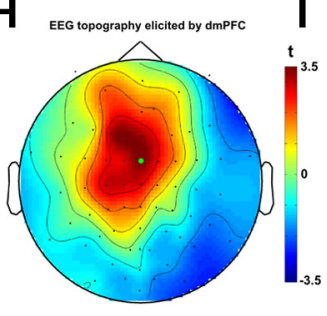

D
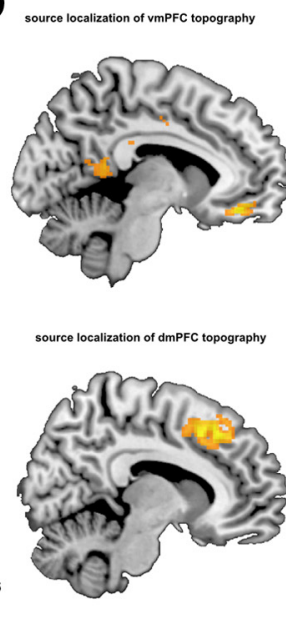

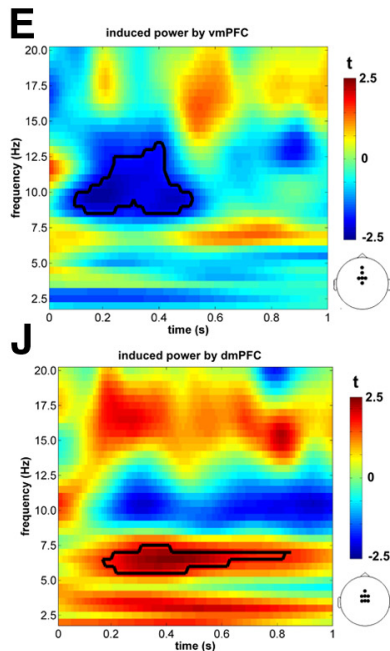

Figure 4. Unique temporal contributions of vmPFC and dmPFC to EEG signal. vmPFC cluster $(\boldsymbol{A})$ revealed a temporally elongated activity $(\boldsymbol{B})$ becoming active at $\sim 250 \mathrm{~ms}$ after feedback (shaded area depicts cluster-corrected significance) and uniquely processing information until $\sim 400 \mathrm{~ms}$ after feedback with a midcentral topography (C; red indicates electrodes Fz and FC $z$ used for time plot B). $\boldsymbol{D}$, Source estimation localized center of topography into vmPFC again (peak at MNI: $x=-8, y=40, z=-14$ ). $E$, Time-frequency decomposition revealed that vmPFC mainly operates in the alpha band, from 8 to $12 \mathrm{~Hz}$ (thick black line; $p<0.05$ using cluster permutation test). The colors indicate the effect of single-trial fMRI responses on the EEG power rather than pure EEG power signals. dmPFC $(\boldsymbol{F})$ shows a short, but marked unique activation between 360 and $400 \mathrm{~ms}$ after feedback $(\boldsymbol{G})$. Its topography is typical for dorsofrontal midline areas $(\boldsymbol{H} ; \mathrm{green}$ indicates electrode $\mathrm{F}(\mathrm{z})$. I, Informed source localization projects topography back to dmPFC (peak at MNI $x=10, y=22, z=44$ ). Time-frequency analysis shows that dmPFC elicits a significant activation in the theta band, from 5 to $8 \mathrm{~Hz}(J)$.

where in the brain specific EEG signals originate from. Instead, our fMRI-informed EEG analysis asks which features of the EEG data are linearly dependent upon trial-to-trial variability in BOLD responses. By including multiple brain regions simultaneously in the same regression model, we can ask a novel set of questions including whether certain EEG features are better explained by some region's activity than others.

We ran a mass-univariate (multiple) regression analysis (Fig. $1 B$ ) on EEG data from 25 healthy adults who performed a probabilistic reversal learning task (Fig. $1 C$ ) while fMRI was recorded simultaneously. First, we extracted the fMRI activation of a given ROI on every trial by deconvolving the local fMRI signal with the hemodynamic response function. Together with a constant term, these estimates formed the design matrix derived from the fMRI data, termed $X^{\text {fmri }}$ dimensions: $\left(n_{\text {ROIs }}+\right.$ intercept $) \times n_{\text {trials }}$. ROIs were determined based on conventional fMRI contrasts from previously designed analyses (cf. Hauser et al., 2014a; visual, motor, reward prediction errors). Then, for each EEG electrode $e$, we ran a separate (multiple) linear regression analysis:

$$
Y_{\mathrm{e}}^{\mathrm{eeg}}=B_{\mathrm{e}}^{\mathrm{eeg}} X^{\mathrm{fmri}}+E_{\mathrm{e}}^{\mathrm{eeg}} .
$$

$Y_{\mathrm{e}}^{\text {eeg }}$ (dimensions: $n_{\text {timepoints }} \times n_{\text {trials }}$ ) denotes the preprocessed EEG data for a given electrode $e$. The effect sizes $B_{\mathrm{e}}^{\text {eeg }}$ (dimensions: $n_{\text {ROIs }+1} \times n_{\text {timepoints }}$ ) and their errors $E_{\mathrm{e}}^{\text {eeg }}$ (dimensions: $n_{\text {timepoints }}$ $\times n_{\text {trials }}$ ) were estimated for each electrode separately using ordinary least-squares regression. The design matrix $X^{\text {fmri }}$ remained constant in the regression on each sensor.

The key idea is that at each EEG sensor, the estimated $B$ matrix reflects the time course of the electrical contribution from each region of interest. Crucially, the approach controls for the electrical contributions of other regions of interest to the sensor, as all regions of interest compete for explained variance in the multiple linear regression. The trial-to-trial activation of correlated sources, such as the ones elicited by RPE processing (Fig. 1E), are sufficiently decorrelated to discern unique contributions to the EEG signal. However, it is important to bear in mind that this method is insensitive to common contributions from multiple regions that have identical temporal and trial-by-trial fMRI profiles. EEG parameter estimates were calculated at the first level by performing the regression separately for each subject. At the second level, we calculated the group time course for each ROI by entering each participant's beta estimates into one-sampled $t$ tests, to test for significant deflections from zero across the population. We corrected for multiple comparisons using FWE correction.

To test the validity of our method, we applied it to two brain areas which elicit unique and characteristic temporal and topographical EEG signals, namely visual elicited activation from occipitotemporal cortex (including fusiform area) and motor activation from handmotor area (see Materials and methods for details). The occipitotemporal cortex elicited a strong negative deflection at left occipitotemporal electrodes, peaking at $190 \mathrm{~ms}$ after stimulus onset (Fig. 3A, middle). This is well in line with the visual N1/N170 component, often associated with activation in occipitotemporal regions (Hillyard and Anllo-Vento, 1998; Brem et al., 2006; Friston et al., 2008). The handmotor area showed a significant activation at the time of button press with a midcentral topography in proximity of the central sulcus (Fig. 3B). It is important to note that no information about the timing or topography is provided in our method. The specific time course and topography thus emerged from the data itself, by identifying which features of EEG activity covaried with trial-by-trial fluctuations in fMRI activity.

\section{Dissociating medial prefrontal cortex activations: time courses of vmPFC and dmPFC}

Having established the sensitivity of our method, we addressed our main question of interest, namely the temporal response profile of vmPFC and dmPFC during reward processing.

Participants played a probabilistic reversal learning task (Fig. $1 C$ ) where they had to learn reward probabilities based on the feedback. vmPFC and dmPFC were identified from a RPE contrast during feedback in a conventional fMRI analysis (Fig. $1 D$; Table 1). vmPFC activity increased with increasing RPEs, 
whereas $\mathrm{dmPFC}$ showed increased activation to decreasing RPEs. This confirms the antagonistic activation pattern of these areas, similar to previous studies (FitzGerald et al., 2009; Hare et al., 2011; Nicolle et al., 2012; Boorman et al., 2013). Moreover, we found coactivation of the PCC with the vmPFC, both of them known to frequently coactivate and as the core of the default mode network (Raichle et al., 2001). The dmPFC showed coactivations with bilateral AI, again known to coactivate as nodes of the saliency network (Seeley et al., 2007). To reliably determine the unique contributions of vmPFC and dmPFC (compare Fig. $1 E$ ), we controlled for the joint activation with PCC and AI by adding them to the EEG multiple regression model as covariates.

We found an unique contribution of vmPFC (Fig. 4A-C) that extended across a prolonged period postfeedback presentation, starting as early as $250 \mathrm{~ms}$ after feedback onset and remaining active until $\sim 400 \mathrm{~ms}$ poststimulus, peaking at $262 \mathrm{~ms}$ (clusterFWE corrected: $p=0.017$; voxel-height threshold: $t=3$; correction time window: $0-800 \mathrm{~ms}$ ). The topography attributed to the vmPFC had a midcentral distribution and is similar to a simulated topography from the given area (Fig. 2B). This was also confirmed using an informed source localization, which localized the topography within the same area (Fig. 4D).

An activation uniquely attributed to dmPFC (Fig. $4 F-H$ ) showed an onset at $\sim 360 \mathrm{~ms}$ postfeedback onset, with a strong peak at $390 \mathrm{~ms}$. This activation terminated at $\sim 400 \mathrm{~ms}$ (clusterFWE corrected: $p=0.045$; voxel-height threshold: $t=3$; time window: $300-400 \mathrm{~ms})$. The dmPFC showed a midcentral topography, similar to our simulated response (Fig. 2A). The topography, was successfully reallocated to the dmPFC in the informed source localization (Fig. 4I).

To examine further for timing differences between vmPFC and $\mathrm{dmPFC}$, we ran a cross-correlation analysis between the fMRI-informed EEG-signals for both regions. The crosscorrelation examines the time-shift that maximizes the correlation between two signals and revealed that cross-correlation was maximal at a lag of $50 \mathrm{~ms}$ at electrode AFz. This supports the notion that the vmPFC precedes dmPFC in terms of activation.

It should be noted that our multiple-regression approach identifies signals that can be explained over and above the contribution of other brain regions and thus may be biased to preferentially reveal differences rather than common activations. We therefore conducted additional analyses which do not control for shared variance (Fig. 5). In these analyses, activation in both regions became stronger and more extended in time, implying a common extended component between the regions that may be masked by our multiple regression approach. vmPFC (Fig. 5A) activity peaked at $260 \mathrm{~ms}$ after feedback remained active until $\sim 400 \mathrm{~ms}\left(t_{(24)}=4.27, p=0.003\right.$, cluster-FWE corrected for multiple comparisons; time window: $0-800 \mathrm{~ms}$ poststimulus). dmPFC (Fig. $5 B$ ) showed a sustained activation from $\sim 300-420$ $\mathrm{ms}\left(t_{(24)}=5.68, p=0.027\right.$, peak-FWE corrected for multiple comparisons; time window: $0-800 \mathrm{~ms}$ poststimulus). Importantly, however a vmPFC response still preceded that seen in dmPFC supporting the notion that these regions make distinct temporal contributions to the reward learning process.

\section{Time-frequency analysis of dmPFC and vmPFC activation}

To further understand the neural dynamics of vmPFC and dmPFC, we extended our method and performed our fMRIinformed EEG analysis on the time-frequency decomposed EEG signal. We repeated the same analysis as described in equation 1 , but the data vector $Y_{\mathrm{e}}^{\mathrm{eeg}}$ was extended by the frequency component $Y_{\mathrm{e}, \mathrm{f}}^{\mathrm{eeg}}$; that is, regression is not only performed at every elec-
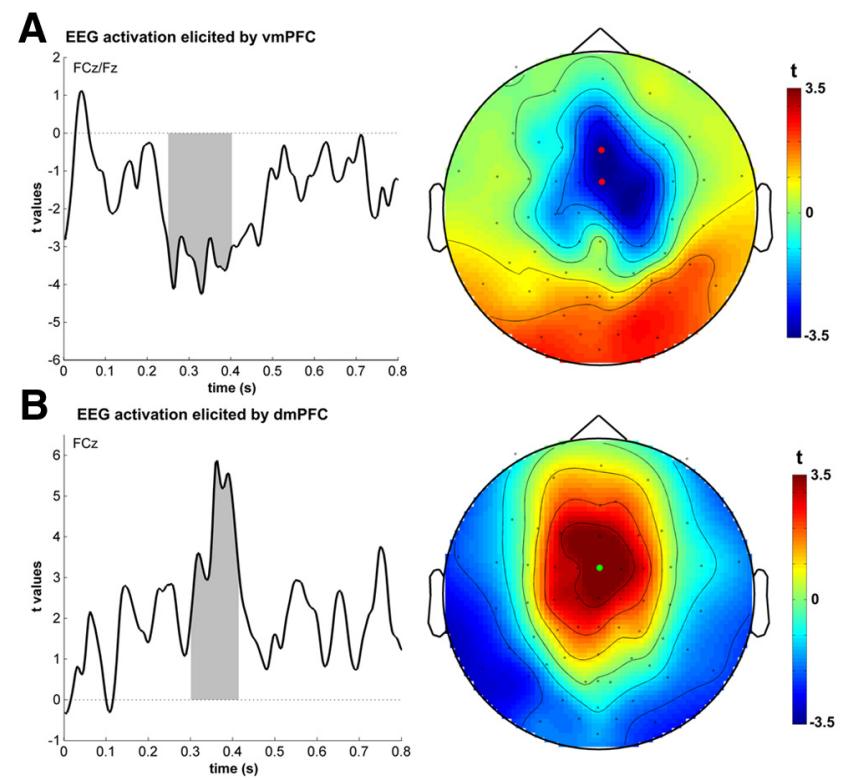

Figure 5. Time course of vmPFC and dmPFC uncorrected for other areas. In our main analysis, we investigated the unique contributions of dmPFC and vmPFC. To investigate the effect of dmPFC and vmPFC when not controlling for the contributions of the related areas, we analyzed the vmPFC and dmPFC separately. We found that both signals show sustained activations after feedback with a similar topography as in our main analysis. This supports an assumption that activation signals recorded during this time consist of a mixture of $\mathrm{dmPFC}$ and vmPFC signals and are not differentiable by using common EEG/MEG analyses. dmPFC ( $\boldsymbol{B})$ showed a sustained activation from $\sim 300$ to 420 ms (shaded area depicts cluster-corrected significance) and $\operatorname{vmPFC}(\boldsymbol{A})$ activity peaked at $260 \mathrm{~ms}$ after feedback and showed a long lasting activity again until $\sim 400 \mathrm{~ms}$.

trode and every time bin as before, but also at every frequency bin. We focus on the time-frequency induced effects of dmPFC and vmPFC in a subset of midfrontal electrodes which correspond to the electrodes that showed a strong effect of vmPFC, and dmPFC activity respectively (electrodes $\mathrm{Fz}, \mathrm{FCz}, \mathrm{Cz}, \mathrm{C} 1, \mathrm{C} 2$, FC1, FC2 for dmPFC, electrodes $\mathrm{AFz}, \mathrm{Fz}, \mathrm{FCz}, \mathrm{FC} 1, \mathrm{FC} 2, \mathrm{Cz}$ for vmPFC; Fig. $4 E$,J, compare bottom right).

Oscillatory correlates of the dmPFC have extensively been investigated in various cognitive domains with dmPFC often associated with theta activation over midfrontal electrodes (Cavanagh et al., 2011; Cohen, 2011; Cavanagh and Frank, 2014; Cavanagh and Shackman, 2015; Frank et al., 2015). There is by comparison little knowledge regarding vmPFC, though first studies indicate it processes information mainly in alpha and lower beta bands (Oya et al., 2005; Hunt et al., 2013; Lipsman et al., 2014).

At the time when dmPFC showed marked activation in the time domain $(360-400 \mathrm{~ms})$, we found increased synchronization in the theta band (Fig. 4J; $p=0.046$, corrected for multiple comparisons using cluster permutation). The vmPFC showed a clear and marked desynchronization mainly in the alpha band (Fig. 4E; $p=0.029$, corrected for multiple comparisons using cluster permutation) extending around the same time as the unique activation of vmPFC was apparent.

\section{Discussion}

vmPFC and dmPFC form two key regions implicated in decision making and reward learning. vmPFC is consistently activated in functional MRI studies of reward processing and decisionmaking (Levy and Glimcher, 2012; Bartra et al., 2013; Clithero and Rangel, 2014). Lesions to this region elicit alterations in 
subjects' decision making behavior as well as in learning from reinforcement (Fellows and Farah, 2003, 2007). Single-unit recordings also provide evidence suggestive of a role in motivation and choice (Bouret and Richmond, 2010; Strait et al., 2014). $\mathrm{dmPFC}$ is likewise activated in fMRI studies of reinforcement learning and action selection (Behrens et al., 2007; Botvinick, 2007; Hare et al., 2011; Vickery et al., 2011; Kolling et al., 2012; Boorman et al., 2013; Economides et al., 2014). Combined with evidence from single-unit recording and lesion studies (Kennerley et al., 2006; Seo and Lee, 2009; Sheth et al., 2012), this has led to the idea that dmPFC subserves a role in learning from outcomes, as well as in deploying learnt values in action selection (Alexander and Brown, 2011; Rushworth et al., 2011). Despite partially different functional connotations of vmPFC and $\mathrm{dmPFC}$, both areas consistently tend to coactivate in fMRI studies of human decision making (FitzGerald et al., 2009; Hare et al., 2011; Nicolle et al., 2012; Boorman et al., 2013), which has rendered it difficult to understand the relation between these two regions within the decision making network.

Here in our fMRI analysis we replicated a common finding of anticorrelated activation profiles of $\mathrm{dmPFC}$ and vmPFC, and also found unique temporal activation profiles for each area. vmPFC became active as early as $250 \mathrm{~ms}$ following a reward outcome and maintained its activation until $400 \mathrm{~ms}$, an activation also reflected in a marked alpha desynchronization in the time-frequency domain. The dmPFC, on the other hand, showed a much shorter, but temporally overlapping activity between 360 and $400 \mathrm{~ms}$ after feedback, an activation profile reflected in the theta band.

The medial prefrontal wall as a whole is densely innervated by mesencephalic dopamine inputs (Lindvall et al., 1974; Bates and Goldman-Rakic, 1993) rendering it plausible both areas process the same dopaminergic information, such as prediction errors (Holroyd and Coles, 2002; Schultz, 2002), based on this common input with (potentially) a similar time course. A different viewpoint assumes vmPFC and dmPFC makes distinct contributions to decision making (Schoenbaum et al., 2009; Grabenhorst and Rolls, 2011; Hare et al., 2011; O’Doherty, 2011). This is supported by evidence that vmPFC calculates option values (Hare et al., 2011) or stores value expectations (Schoenbaum et al., 2009) which are then transmitted to other regions including dmPFC (potentially via a dopaminergic relay; Schoenbaum et al., 2009). Such a decision-making hierarchy entails vmPFC and dmPFC should show temporally distinct activation patterns, with vmPFC activated at an earlier stage than dmPFC. Our findings lend support to this idea of a preceding vmPFC response that provides a value signal, which may then be propagated to dmPFC, which in turn integrates this information into action values for subsequent action selection.

Our findings demonstrate that vmPFC and dmPFC process unique information which is functionally dissociable from one another as well as other coactivated areas. Although we find coactivation of these regions in conventional fMRI analyses, it is nevertheless the case that the responsivity of these regions is dissociable in time. Both vmPFC and dmPFC process information separately, over and above any simultaneous processing of information that our method may be less sensitive too. This temporal separation speaks against the idea that these areas simultaneously process information purely as predicted by accounts where reward-related activation is driven by a common input. Rather, it supports the idea that there is a processing hierarchy instantiated within the medial prefrontal cortex itself whereby an earlier activation of vmPFC might be propagated forward to the dmPFC for further evaluation. However, it will be important to replicate these findings in animal studies with multisite recordings. Therein, one can measure region-specific neural activity directly without having to control for coactivated brain areas. We would therefore expect to see similar, but temporally extended activation patterns, as our approach ignores variance shared by multiple ROIs.

Previous EEG studies focused on the FRN (Miltner et al., 1997; Holroyd and Coles, 2002; Talmi et al., 2013; Sambrook and Goslin, 2014) as a component which reflects feedback processing in the dmPFC (Walsh and Anderson, 2012). Interestingly, the FRN often shows a different temporal activation pattern to our observed dmPFC signal, as it occurs between 250 and $350 \mathrm{~ms}$ after feedback. This discrepancy may be resolved when we understand that such ERP components are likely to represent a mixture signal caused by several areas which are active at approximately the same time (compare Fig. 1A). It is also likely that the FRN reflects a mixture of active areas, potentially even a combination of vmPFC and dmPFC activation. Given our finding that vmPFC is active at $\sim 250 \mathrm{~ms}$, a mixture of vmPFC and dmPFC activity would explain the earlier occurrence of the FRN compared with our dmPFC activation. Moreover, it also explains why previous source localizations often report more anterior and ventral FRN origins, even localizing it in proximity of the vmPFC (cf. Walsh and Anderson, 2012), rendering it likely that a mixture of vmPFC and dmPFC signal is located between the two sources. Evidence for this assumption comes from our analysis in which we do not control for the other regions where we showed a temporally more elongated signal for the dmPFC, well within the range of the FRN (Fig. 5). Given that this signal does not emerge when controlling for other areas, it is clear that this time course does not reflect activity from dmPFC alone. This also highlights that common EEG source and scalp analyses often struggle to differentiate temporally related signals. Critically, EEG analyses are less sensitive to deep sources such as the vmPFC, especially if such signals are superimposed upon by stronger signals from regions closer to the scalp. The key advantage of our approach is that we have a signal that we know originates from vmPFC, rather than inferring on the signal using an inverse solution. This enables us to clearly delineate the signals from vmPFC and $\mathrm{dmPFC}$ and therefore to define unique temporal contributions of these areas.

The finding that the dmPFC operates in the theta frequency band fits with a broad corpus of literature which posits frontal midline theta as being related to decision making and cognitive control (Cavanagh and Frank, 2014). One of the difficulties of the frontal midline theta, however, has been a lack of spatial specificity. Our results show that the dmPFC elicits feedback-related theta activity, even when controlling for coactivated areas such as the insular cortex or vmPFC. Much less is known about the temporal and oscillatory aspects of the vmPFC as these signals are often obscured by other signals with sources closer to the scalp electrodes. By controlling for the activity of the coactivated regions, we recovered a vmPFC signal that operates mainly in the alpha band. We note that the few studies that have investigated vmPFC activity using MEG and intracortical recordings (Oya et al., 2005; Hunt et al., 2012, 2013; Harris et al., 2013; Lipsman et al., 2014) have reported similar frequency bands as reported in our results.

In this study, we show that our fMRI-informed EEG approach can be of great value for answering questions about the timing of specific brain regions, and that it is robust against correlated sources and complementary scalp distributions. Our approach assumes a linear relationship between amplitude/power and BOLD signal strength. Although animal studies have suggested 
that the relation between BOLD and local field potentials is partly nonlinear and frequency-dependent (for review, see Rosa et al., 2010), a broad corpus of simultaneous EEG-fMRI studies demonstrate that despite simplifying assumptions, linear associations provide for sensitive and reliable results (Debener et al., 2006; Rosa et al., 2010). However, it should be noted that a directionality in coupling between EEG frequencies and BOLD is nontrivial (Scheeringa et al., 2011). This may explain why we observed a negative relationship between EEG alpha power and BOLD in the vmPFC, similar to previous EEG-fMRI reports ( Lüchinger et al., 2011; Scheeringa et al., 2011), but opposite to invasive recording findings (Oya et al., 2005). Moreover, it is noteworthy that our approach requires a relatively strong trial-by-trial variability of EEG- and fMRI-signals to determine the specific time courses. In our main analysis, we analyzed reward and punishment trials together. A separate analysis of rewards and punishments results in similar (albeit slightly weaker; data not shown) results for rewards, whereas punishment-only trials lack in power to show the same patterns. An increase in trial number of either kind would thus be beneficial for future studies.

In summary, we provide evidence for dissociable temporal patterns of the frontal midline areas dmPFC and vmPFC. Both areas express dissociable temporal signals with vmPFC preceding a dmPFC activation. This pattern supports the assumption of a functional architecture in the medial prefrontal cortex whereby vmPFC (operating in alpha bands) is involved primarily in valuation and value comparison and precedes dmPFC (operating in theta), which then uses this information in subsequent trials to select the most valuable actions.

\section{References}

Alexander WH, Brown JW (2011) Medial prefrontal cortex as an actionoutcome predictor. Nat Neurosci 14:1338-1344. CrossRef Medline

Allen PJ, Josephs O, Turner R (2000) A method for removing imaging artifact from continuous EEG recorded during functional MRI. Neuroimage 12:230-239. CrossRef Medline

Bartra O, McGuire JT, Kable JW (2013) The valuation system: a coordinatebased meta-analysis of BOLD fMRI experiments examining neural correlates of subjective value. Neuroimage 76:412-427. CrossRef Medline

Bates JF, Goldman-Rakic PS (1993) Prefrontal connections of medial motor areas in the rhesus monkey. J Comp Neurol 336:211-228. CrossRef Medline

Baumeister S, Hohmann S, Wolf I, Plichta MM, Rechtsteiner S, Zangl M, Ruf M, Holz N, Boecker R, Meyer-Lindenberg A, Holtmann M, Laucht M, Banaschewski T, Brandeis D (2014) Sequential inhibitory control processes assessed through simultaneous EEG-fMRI. Neuroimage 94:349359. CrossRef Medline

Becker MP, Nitsch AM, Miltner WH, Straube T (2014) A single-trial estimation of the feedback-related negativity and its relation to BOLD responses in a time-estimation task. J Neurosci 34:3005-3012. CrossRef Medline

Behrens TE, Woolrich MW, Walton ME, Rushworth MF (2007) Learning the value of information in an uncertain world. Nat Neurosci 10:12141221. CrossRef Medline

Bentin S, Allison T, Puce A, Perez E, McCarthy G (1996) Electrophysiological studies of face perception in humans. J Cogn Neurosci 8:551-565. CrossRef Medline

Boecker R, Holz NE, Buchmann AF, Blomeyer D, Plichta MM, Wolf I, Baumeister S, Meyer-Lindenberg A, Banaschewski T, Brandeis D, Laucht M (2014) Impact of early life adversity on reward processing in young adults: EEG-fMRI results from a prospective study over 25 years. PloS One 9:e104185. CrossRef Medline

Boorman ED, Rushworth MF, Behrens TE (2013) Ventromedial prefrontal and anterior cingulate cortex adopt choice and default reference frames during sequential multi-alternative choice. J Neurosci 33:2242-2253. CrossRef Medline
Botvinick MM (2007) Conflict monitoring and decision making: reconciling two perspectives on anterior cingulate function. Cogn Affect Behav Neurosci 7:356-366. CrossRef Medline

Bouret S, Richmond BJ (2010) Ventromedial and orbital prefrontal neurons differentially encode internally and externally driven motivational values in monkeys. J Neurosci 30:8591-8601. CrossRef Medline

Brem S, Bucher K, Halder P, Summers P, Dietrich T, Martin E, Brandeis D (2006) Evidence for developmental changes in the visual word processing network beyond adolescence. Neuroimage 29:822-837. CrossRef Medline

Cavanagh JF, Frank MJ (2014) Frontal theta as a mechanism for cognitive control. Trends Cogn Sci 18:414-421. CrossRef Medline

Cavanagh JF, Shackman AJ (2015) Frontal midline theta reflects anxiety and cognitive control: meta-analytic evidence. J Physiol Paris 109:3-15. CrossRef Medline

Cavanagh JF, Wiecki TV, Cohen MX, Figueroa CM, Samanta J, Sherman SJ, Frank MJ (2011) Subthalamic nucleus stimulation reverses mediofrontal influence over decision threshold. Nat Neurosci 14:1462-1467. CrossRef Medline

Clithero JA, Rangel A (2014) Informatic parcellation of the network involved in the computation of subjective value. Soc Cogn Affect Neurosci 9:1289-1302. CrossRef Medline

Cohen MX (2011) Error-related medial frontal theta activity predicts cingulate-related structural connectivity. Neuroimage 55:1373-1383. CrossRef Medline

Debener S, Ullsperger M, Siegel M, Fiehler K, von Cramon DY, Engel AK (2005) Trial-by-trial coupling of concurrent electroencephalogram and functional magnetic resonance imaging identifies the dynamics of performance monitoring. J Neurosci 25:11730-11737. CrossRef Medline

Debener S, Ullsperger M, Siegel M, Engel AK (2006) Single-trial EEG-fMRI reveals the dynamics of cognitive function. Trends Cogn Sci 10:558-563. CrossRef Medline

Diaconescu AO, Mathys C, Weber LA, Daunizeau J, Kasper L, Lomakina EI, Fehr E, Stephan KE (2014) Inferring on the intentions of others by hierarchical Bayesian learning. PLoS Comput Biol 10:e1003810. CrossRef Medline

Economides M, Guitart-Masip M, Kurth-Nelson Z, Dolan RJ (2014) Anterior cingulate cortex instigates adaptive switches in choice by integrating immediate and delayed components of value in ventromedial prefrontal cortex. J Neurosci 34:3340-3349. CrossRef Medline

Eichele T, Specht K, Moosmann M, Jongsma ML, Quiroga RQ, Nordby H, Hugdahl K (2005) Assessing the spatiotemporal evolution of neuronal activation with single-trial event-related potentials and functional MRI. Proc Natl Acad Sci U S A 102:17798-17803. CrossRef Medline

Fellows LK, Farah MJ (2003) Ventromedial frontal cortex mediates affective shifting in humans: evidence from a reversal learning paradigm. Brain 126:1830-1837. CrossRef Medline

Fellows LK, Farah MJ (2007) The role of ventromedial prefrontal cortex in decision making: judgment under uncertainty or judgment per se? Cereb Cortex 17:2669-2674. CrossRef Medline

FitzGerald TH, Seymour B, Dolan RJ (2009) The role of human orbitofrontal cortex in value comparison for incommensurable objects. J Neurosci 29:8388-8395. CrossRef Medline

Frank MJ, Gagne C, Nyhus E, Masters S, Wiecki TV, Cavanagh JF, Badre D (2015) fMRI and EEG predictors of dynamic decision parameters during human reinforcement learning. J Neurosci 35:485-494. CrossRef Medline

Friston K, Harrison L, Daunizeau J, Kiebel S, Phillips C, Trujillo-Barreto N, Henson R, Flandin G, Mattout J (2008) Multiple sparse priors for the M/EEG inverse problem. Neuroimage 39:1104-1120. CrossRef Medline

Gläscher J, Hampton AN, O’Doherty JP (2009) Determining a role for ventromedial prefrontal cortex in encoding action-based value signals during reward-related decision making. Cereb Cortex 19:483-495. CrossRef Medline

Glover GH, Li TQ, Ress D (2000) Image-based method for retrospective correction of physiological motion effects in fMRI: RETROICOR. Magn Reson Med 44:162-167. CrossRef Medline

Grabenhorst F, Rolls ET (2011) Value, pleasure and choice in the ventral prefrontal cortex. Trends Cogn Sci 15:56-67. CrossRef Medline

Haber SN, Behrens TE (2014) The neural network underlying incentivebased learning: implications for interpreting circuit disruptions in psychiatric disorders. Neuron 83:1019-1039. CrossRef Medline 
Hare TA, Schultz W, Camerer CF, O’Doherty JP, Rangel A (2011) Transformation of stimulus value signals into motor commands during simple choice. Proc Natl Acad Sci U S A 108:18120-18125. CrossRef Medline

Harris A, Hare T, Rangel A (2013) Temporally dissociable mechanisms of self-control: early attentional filtering versus late value modulation. J Neurosci 33:18917-18931. CrossRef Medline

Hauser TU, Iannaccone R, Ball J, Mathys C, Brandeis D, Walitza S, Brem S (2014a) Role of the medial prefrontal cortex in impaired decision making in juvenile attention-deficit/hyperactivity disorder. JAMA Psychiatry 71:1165-1173. CrossRef Medline

Hauser TU, Iannaccone R, Stämpfli P, Drechsler R, Brandeis D, Walitza S, Brem S (2014b) The feedback-related negativity (FRN) revisited: new insights into the localization, meaning and network organization. Neuroimage 84:159-168. CrossRef Medline

Hauser TU, Iannaccone R, Walitza S, Brandeis D, Brem S (2015) Cognitive flexibility in adolescence: neural and behavioral mechanisms of reward prediction error processing in adaptive decision making during development. Neuroimage 104:347-354. CrossRef Medline

Hillyard SA, Anllo-Vento L (1998) Event-related brain potentials in the study of visual selective attention. Proc Natl Acad Sci U S A 95:781-787. CrossRef Medline

Holmes AP, Friston KJ (1998) Generalisability, random effects and population inference. Neuroimage 7:754.

Holroyd CB, Coles MG (2002) The neural basis of human error processing: reinforcement learning, dopamine, and the error-related negativity. Psychol Rev 109:679-709. CrossRef Medline

Hunt LT, Kolling N, Soltani A, Woolrich MW, Rushworth MF, Behrens TE (2012) Mechanisms underlying cortical activity during value-guided choice. Nat Neurosci 15:470-476, S1-S3. CrossRef Medline

Hunt LT, Woolrich MW, Rushworth MF, Behrens TE (2013) Trial-type dependent frames of reference for value comparison. PLoS Comput Biol 9:e1003225. CrossRef Medline

Huster RJ, Debener S, Eichele T, Herrmann CS (2012) Methods for simultaneous EEG-fMRI: an introductory review. J Neurosci 32:6053-6060. CrossRef Medline

Iannaccone R, Hauser TU, Staempfli P, Walitza S, Brandeis D, Brem S (2015) Conflict monitoring and error processing: new insights from simultaneous EEG-fMRI. Neuroimage 105:395-407. CrossRef Medline

Iglesias S, Mathys C, Brodersen KH, Kasper L, Piccirelli M, den Ouden HE, Stephan KE (2013) Hierarchical prediction errors in midbrain and basal forebrain during sensory learning. Neuron 80:519-530. CrossRef Medline

Johnson JS, Olshausen BA (2003) Timecourse of neural signatures of object recognition. J Vis 3(7):4 499-512. CrossRef Medline

Kasper L, Marti S, Vannesjö SJ, Hutton C, Dolan RJ, Weiskopf N, Stephan KE, Prüssmann KP (2009) Cardiac artefact correction for human brainstem fMRI at 7 tesla. Proc Org Hum Brain Mapp, San Franscisco, CA.

Kennerley SW, Walton ME, Behrens TE, Buckley MJ, Rushworth MF (2006) Optimal decision making and the anterior cingulate cortex. Nat Neurosci 9:940-947. CrossRef Medline

Kilner JM, Friston KJ (2010) Topological inference for EEG and MEG. Ann Appl Stat 4:1272-1290. CrossRef

Kolling N, Behrens TE, Mars RB, Rushworth MF (2012) Neural mechanisms of foraging. Science 336:95-98. CrossRef Medline

Levy DJ, Glimcher PW (2012) The root of all value: a neural common currency for choice. Curr Opin Neurobiol 22:1027-1038. CrossRef Medline

Lindvall O, Björklund A, Moore RY, Stenevi U (1974) Mesencephalic dopamine neurons projecting to neocortex. Brain Res 81:325-331. CrossRef Medline

Lipsman N, Kaping D, Westendorff S, Sankar T, Lozano AM, Womelsdorf T (2014) Beta coherence within human ventromedial prefrontal cortex precedes affective value choices. Neuroimage 85:769-778. CrossRef Medline

Litvak V, Mattout J, Kiebel S, Phillips C, Henson R, Kilner J, Barnes G, Oostenveld R, Daunizeau J, Flandin G, Penny W, Friston K (2011) EEG and MEG data analysis in SPM8. Comput Intell Neurosci 2011:852961. CrossRef Medline

Lüchinger R, Michels L, Martin E, Brandeis D (2011) EEG-BOLD correlations during (post-)adolescent brain maturation. Neuroimage 56:14931505. CrossRef Medline

Mandelkow H, Halder P, Boesiger P, Brandeis D (2006) Synchronization facilitates removal of MRI artefacts from concurrent EEG recordings and increases usable bandwidth. Neuroimage 32:1120-1126. CrossRef Medline

Mathys C, Daunizeau J, Friston KJ, Stephan KE (2011) A Bayesian foundation for individual learning under uncertainty. Front Hum Neurosci 5:39. CrossRef Medline

Mathys CD, Lomakina EI, Daunizeau J, Iglesias S, Brodersen KH, Friston KJ, Stephan KE (2014) Uncertainty in perception and the hierarchical Gaussian filter. Front Hum Neurosci 8:825. CrossRef Medline

Miltner WH, Braun CH, Coles MG (1997) Event-related brain potentials following incorrect feedback in a time-estimation task: evidence for a "generic" neural system for error detection. J Cogn Neurosci 9:788-798. CrossRef Medline

Nicolle A, Klein-Flügge MC, Hunt LT, Vlaev I, Dolan RJ, Behrens TE (2012) An agent independent axis for executed and modeled choice in medial prefrontal cortex. Neuron 75:1114-1121. CrossRef Medline

O'Doherty JP (2011) Contributions of the ventromedial prefrontal cortex to goal-directed action selection. Ann N Y Acad Sci 1239:118-129. CrossRef Medline

Ongür D, Price JL (2000) The organization of networks within the orbital and medial prefrontal cortex of rats, monkeys and humans. Cereb Cortex 10:206-219. CrossRef Medline

Oostenveld R, Fries P, Maris E, Schoffelen JM (2011) FieldTrip: open source software for advanced analysis of MEG, EEG, and invasive electrophysiological data. Comput Intell Neurosci 2011:156869. CrossRef Medline

Oya H, Adolphs R, Kawasaki H, Bechara A, Damasio A, Howard MA 3rd (2005) Electrophysiological correlates of reward prediction error recorded in the human prefrontal cortex. Proc Natl Acad Sci U S A 102: 8351-8356. CrossRef Medline

Raichle ME, MacLeod AM, Snyder AZ, Powers WJ, Gusnard DA, Shulman GL (2001) A default mode of brain function. Proc Natl Acad Sci U S A 98:676-682. CrossRef Medline

Rangel A, Hare T (2010) Neural computations associated with goal-directed choice. Curr Opin Neurobiol 20:262-270. CrossRef Medline

Rescorla RA, Wagner AR (1972) A theory of Pavlovian conditioning: variations in the effectiveness of reinforcement and nonreinforcement. In: Classical conditioning II: current research and theory (Black AH, Prokasy WF, eds), pp 64-99. New York: Appleton-Century-Crofts.

Rosa MJ, Daunizeau J, Friston KJ (2010) EEG-fMRI integration: a critical review of biophysical modeling and data analysis approaches. J Integr Neurosci 9:453-476. CrossRef Medline

Rossion B, Gauthier I, Tarr MJ, Despland P, Bruyer R, Linotte S, Crommelinck M (2000) The N170 occipito-temporal component is delayed and enhanced to inverted faces but not to inverted objects: an electrophysiological account of face-specific processes in the human brain. Neuroreport 11:69-74. CrossRef Medline

Rushworth MF, Behrens TE (2008) Choice, uncertainty and value in prefrontal and cingulate cortex. Nat Neurosci 11:389-397. CrossRef Medline

Rushworth MF, Behrens TE, Rudebeck PH, Walton ME (2007) Contrasting roles for cingulate and orbitofrontal cortex in decisions and social behaviour. Trends Cogn Sci 11:168-176. CrossRef Medline

Rushworth MF, Noonan MP, Boorman ED, Walton ME, Behrens TE (2011) Frontal cortex and reward-guided learning and decision-making. Neuron 70:1054-1069. CrossRef Medline

Sambrook TD, Goslin J (2014) Mediofrontal event-related potentials in response to positive, negative and unsigned prediction errors. Neuropsychologia 61:1-10. CrossRef Medline

Scheeringa R, Fries P, Petersson KM, Oostenveld R, Grothe I, Norris DG, Hagoort P, Bastiaansen MC (2011) Neuronal dynamics underlying high- and low-frequency EEG oscillations contribute independently to the human BOLD signal. Neuron 69:572-583. CrossRef Medline

Schoenbaum G, Roesch MR, Stalnaker TA, Takahashi YK (2009) A new perspective on the role of the orbitofrontal cortex in adaptive behaviour. Nat Rev Neurosci 10:885-892. CrossRef Medline

Schultz W (2002) Getting formal with dopamine and reward. Neuron 36: 241-263. CrossRef Medline

Seeley WW, Menon V, Schatzberg AF, Keller J, Glover GH, Kenna H, Reiss AL, Greicius MD (2007) Dissociable intrinsic connectivity networks for salience processing and executive control. J Neurosci 27:2349-2356. CrossRef Medline

Seo H, Lee D (2009) Behavioral and neural changes after gains and losses of conditioned reinforcers. J Neurosci 29:3627-3641. CrossRef Medline 
Sheth SA, Mian MK, Patel SR, Asaad WF, Williams ZM, Dougherty DD, Bush G, Eskandar EN (2012) Human dorsal anterior cingulate cortex neurons mediate ongoing behavioural adaptation. Nature 488:218-221. CrossRef Medline

Strait CE, Blanchard TC, Hayden BY (2014) Reward value comparison via mutual inhibition in ventromedial prefrontal cortex. Neuron 82:13571366. CrossRef Medline

Talmi D, Atkinson R, El-Deredy W (2013) The feedback-related negativity signals salience prediction errors, not reward prediction errors. J Neurosci 33:8264-8269. CrossRef Medline

Thorpe S, Fize D, Marlot C (1996) Speed of processing in the human visual system. Nature 381:520-522. CrossRef Medline

Vickery TJ, Chun MM, Lee D (2011) Ubiquity and specificity of reinforce- ment signals throughout the human brain. Neuron 72:166-177. CrossRef Medline

Vossel S, Mathys C, Daunizeau J, Bauer M, Driver J, Friston KJ, Stephan KE (2014) Spatial attention, precision, and Bayesian inference: a study of saccadic response speed. Cereb Cortex 24:1436-1450. CrossRef Medline Wallis JD, KennerleySW (2010) Heterogeneous reward signals in prefrontal cortex. Curr Opin Neurobiol 20:191-198. CrossRef Medline

Walsh MM, Anderson JR (2012) Learning from experience: event-related potential correlates of reward processing, neural adaptation, and behavioral choice. Neurosci Biobehav Rev 36:1870-1884. CrossRef Medline

Yousry TA, Schmid UD, Alkadhi H, Schmidt D, Peraud A, Buettner A, Winkler P (1997) Localization of the motor hand area to a knob on the precentral gyrus. A new landmark. Brain 120:141-157. CrossRef Medline 